of these findings to the possible autoimmune nature of hyperthyroidism itself is discussed.

We are grateful to Dr. Audrey Dawson for the serum vitamin$B_{12}$ estimations and to Dr. S. D. Mohamed for the vitamin-B absorption studies. We also thank Miss Sheila Tait for technical help with the serological studies.

\section{REFERENCES}

Adams, J. F., Glen, A. I. M., Kennedy, E. H., Mackenzie, I. L., Morrow, J. M., Anderson, J. R., Gray, K. G., and Middleton, D. G. (1964). Lancet, 1, 401 .

Anderson, J. R., Gray, K. G., Middleton, D. G., and Young, J. A. (1964). Brit. med. 7., 2, 1630.

Bock, O. A. A., Arapakis, G., Witts, L. J., and Richards, W. C. D. (1963). Gut, 4, 106.

- and Witts, L.'J. (1963). Brit. med. 7., 2, 20

Crooks, J., Murray, I. P. C., and Wayne, E. J. (1959). Quart. F. Med., 28, 211 .
Dagg, J. H., Goldberg, A., Anderson, J. R., Beck, J. S., and Gray, K. G. (1964). Brit. med. ¥., 1 , 1349

Doniach, D., and Roitt, I. M. (1961). In Modern Trends in Endocrinology, second series, edited by H. Gardiner-Hill, p. 278. Butterworths, London.

- and Taylor, K. B. (1963). Brit. med. F., 1, 1374

Glass, G. B. J., Boyd, L. J., Gellin, G. A., and Stephanson, L. (1954). Arch. Biochem., 51, 251 .

Gunn, A., Michie, W., and Irvine, W. J. (1964). Lancet, 2, 776.

Irvine, W. J. (1963a). In The Thyroid and its Diseases, edited by A. Stuart Mason, p. 129. Pitman, London. (1963b). Quart. 7. exp. Physiol., 48, 427.

- (1963c). \%. Endocr., 26, xxii.

Davies, S. H., Delamore, I. W., and Wynn Williams, A. (1962). Brit. med. F., 2, 454.

McNicol, G. P. (1961). Amer. Y. med. Sci., 241, 336.

Marks, I. N., and Shay, H. (1961). Cited by I. N. Marks, Gastroentero$\operatorname{logy}, 1961,41,599$.

Sircus, w. (1959). 7. roy. Coll. Surg. Edinb., 4, 153.

Taylor, K. B., Roitt, I. M., Doniach, D., Couchman, K. G., and Shapland, C. (1962). Brit. med. F., 2, 1347.

te Velde, K., Abels, J., Hoedemaeker, Ph.J., Arends, A., and Niewig, H. O. (1964). Lancet, 1, 941 .

Williams, M. J., and Blair, D. W. (1964). Brit. med. 7., 1, 940.

Young, M. R. (1961). Quart. F. micro. Sci., 102, 419.

\title{
Prevention of Denervation in Bell's Palsy
}

\author{
D. TAVERNER,* M.B.E., M.D., F.R.C.P. ; M. E. FEARNLEY, † M.D., M.R.C.P. ; F. KEMBLE,* M.B., CH.B. \\ D. W. MILES,* M.B., B.SC., M.R.C.P. ; O. A. PEIRIS,* M.D., M.R.C.P., M.R.C.P.ED.
}

Brit. med. F., 1966, 1, 391-393

The natural history of idiopathic facial paralysis (Bell's palsy) has been fully described (Taverner, 1955, 1959). Movement always returns to the paralysed muscles eventually, and about three-fifths of the patients recover completely. The remainder develop denervation of the facial muscles and never recover completely. They all show associated movements of some kind, many develop contractures, and some complain of the " crocodile tear" phenomenon (Taverner, 1959). About onequarter of those who develop denervation remain permanently dissatisfied with their eventual state of recovery (Langworth and Taverner, 1963).

Many forms of treatment have been used for Bell's palsy, but there is no satisfactory evidence that any of them are effective. Controlled trials of the effect of cortisone (Taverner, 1954), physiotherapy (Mosforth and Taverner, 1958), and cervical sympathetic blockade (Fearnley et al., 1964) have all shown negative results. There is urgent need for an effective treatment to prevent the onset or minimize the degree of denervation of the facial muscles.

In this paper we report the results of a controlled trial of the effect of adrenocorticotrophic hormone (A.C.T.H. gel) in patients with Bell's palsy. A brief preliminary report has been published by Taverner and Fearnley (1965).

\section{Design of Trial}

The trial was conducted simultaneously in the Department of Electromyography, General Infirmary at Leeds, and in the Department of Physical Medicine, Orpington Hospital. All patients with Bell's palsy up to six days in duration were admitted to the trial. In each centre their names were entered on a previously prepared list allocating them randomly to treatment or control groups. They were examined clinically

- Department of Electromyography, General Infirmary at Leeds. t Department of Physical Medicine, Orpington Hospital, Orpington, and electromyographically at regular intervals for at least three months. Electromyography consisted in needle sampling of the muscles at the angle of the mouth and estimation of the conduction time from the angle of the jaw to the sampling site (Langworth and Taverner, 1963). Complete denervation is shown by complete loss of electrical excitability of the facial nerve. In partial denervation the nerve continues to respond throughout, but slowing of conduction occurs and some degree of associated movement inevitably appears (Langworth and Taverner, 1963). The threshold to anodal galvanic stimulation on the two sides of the tongue was compared in the Leeds series (Krarup, 1958 ; Peiris and Miles, 1965).

At least three months after the onset of paralysis the final evaluation was made on clinical grounds alone, and two observers agreed about each one. The results were classified as (1) complete recovery, full voluntary movement and no associated movements ; or (2) denervation, any defect of voluntary movement plus any degree of associated movement, however slight. All the patients with denervation, irrespective of degree, were classified as failures, and preference was given to the other member of the pair. Non-tied pairs from both centres in chronological order of entry were analysed sequentially by means of a closed design designated by the parameters $2 \alpha=$ $0.05,1-\beta=0.95, \theta=0.85, \mathrm{~N}=27$ (Armitage, 1960).

\section{Patients}

All patients aged 14 years or more with idiopathic facial palsy of up to six days' duration were admitted to the trial, the criteria laid down by Taverner (1955) being used. One control patient subsequently developed herpes zoster of the external auditory meatus and showed evidence of denervation. One treated patient was lost track of by administrative error. When last seen this patient was recovering rapidly, and denervation is most unlikely. The pairs containing these patients were not used in the sequential analysis chart, though the unaffected 
member of each pair has been retained for the more detailed statistical analysis.

Treatment.-The treated patients were given 10 daily intramuscular injections of A.C.T.H. gel starting on the day of entry. The dosage was 80 units a day for five days, then 60 , 40 , and 20 units on the next three days, and 10 units daily for the last two days. The control patients received no drugs apart from simple analgesics if needed. Both groups of patients were advised to massage their faces gently every day.

\section{Results}

Seventy-two patients entered the trial originally-58 in Leeds and 14 in Orpington-but two have been excluded from the statistical analysis. Thirty-four received A.C.T.H. and 36 acted as controls. The average age of the treated group was 41.8 years (range 14-66 years) and of the control group 38.0 years (range 15-69 years). This agrees closely with the age range of a previous series (Taverner, 1959).

As each pair in Leeds reached final assessment the results were plotted on the sequential analysis chart (see Fig.) and a significant preference $(P=0.05)$ was shown for the A.C.T.H. treatment. The trial was then stopped on ethical grounds because we were no longer prepared to refuse to treat any suitable patient. At this stage in Leeds the results were as shown in Table I, but many pairs were still under observation.



Effect of A.C.T.H. in facial palsy. Heavy line indicates seven successive pairs showing preference for A.C.T.H.

When the final results were collected from both centres (Table II) it became apparent that the sequential analysis carried out on the early results had by chance exaggerated the effectiveness of A.C.T.H. treatment. In all, 34 patients had received A.C.T.H., and 27 of them recovered completely, while seven developed denervation. Of the 36 control patients

TABLE I.-Incidence of Denervation in Relation to Treatment

\begin{tabular}{|c|c|c|c|c|c|c|}
\hline \multirow{2}{*}{\multicolumn{3}{|c|}{ Treatment }} & \multicolumn{2}{|c|}{ Tied Pairs } & \multicolumn{2}{|c|}{ Untied Pairs } \\
\hline & & & Denervated & Not & Denervated & Not \\
\hline $\begin{array}{l}\text { A.C.T.H. } \\
\text { Control . }\end{array}$ & 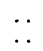 & $\therefore$ & $\begin{array}{l}0 \\
0\end{array}$ & $\begin{array}{l}8 \\
8\end{array}$ & $\begin{array}{l}0 \\
7\end{array}$ & $\begin{array}{l}7 \\
0\end{array}$ \\
\hline
\end{tabular}

TABLE I1.-Outcome of Treatment with A.C.T.H. Gel in Unselected Consecutive Patients

\begin{tabular}{|c|c|c|c|c|c|}
\hline & Treatment & & Total & $\begin{array}{l}\text { Complete } \\
\text { Recovery }\end{array}$ & Denervation \\
\hline $\begin{array}{l}\text { A.C.T.H. } \\
\text { Control .. }\end{array}$ & $\because$ & $\because$ & $\begin{array}{l}34 \\
36\end{array}$ & $\begin{array}{l}27 \\
22\end{array}$ & $\begin{array}{r}7 \\
14\end{array}$ \\
\hline
\end{tabular}

$\chi^{2}=4.93, n=1, P<0.05$. For details of analysis, see text.
14 developed denervation and 22 recovered completely. This difference in the proportions of recoveries is not significant by the usual tests $\left(\chi^{2}=1.98, \mathrm{n}=1, \mathrm{P}>0.05\right)$. However, the incidence of denervation in the present control series $(39 \%)$ is almost identical with the denervation rate in three previous series of Bell's palsy (Taverner, 1954 ; Mosforth and Taverner, 1958 ; Fearnley et al., 1964). The method of selection of patients in these trials was the same, the average age of the patients was 39.5 years, and the denervation rate was $42 \%$. It is therefore reasonable to assume that the control series in the present trial is representative of the normal population of patients with Bell's palsy. If the incidence of denervation in the present control series is taken as the "expected value" the result is $\chi^{2}=4.93, n=1, P<0.05$. The difference in the number of patients with denervation in the treated and control groups can be regarded as statistically significant.

After the first trial was stopped all new patients seen in Leeds with Bell's palsy of up to five days' duration were treated with A.C.T.H. if they showed an abnormal response to anodal galvanic stimulation of the tongue. If there was any doubt about their clinical state on the grounds of reliability of the test response, age, or severity of paralysis they were treated. Patients with incomplete paralysis were not treated.

A further 73 patients have been seen up to the end of April 1965, and have been followed up for three months or more. Thirty were judged to be suffering from conduction block because the anodal galvanic threshold was normal, and all have, in fact, recovered completely without treatment. Of the 43 treated with A.C.T.H. 27 had definitely abnormal galvanic thresholds on the affected side and could be expected to develop denervation if untreated (Peiris and Miles, 1965). The remaining 16 were included because of clinical uncertainty. In this group of 43 treated patients 37 have recovered completely and only six have developed denervation.

Altogether 77 patients have been treated with A.C.T.H. ; 64 recovered completely and 13 developed some degree of denervation (Table III). If we use the argument stated above, and ignore the fact that the present series has an unduly high proportion of patients liable to undergo denervation, it would be expected that at least $30(39 \%)$ would develop denervation. In fact only 13 did so, and the difference is statistically highly significant $\left(\chi^{2}=14.86, \mathrm{n}=1, \mathrm{P}<0.001\right)$.

TABre III.-Results in All Patients Treated with A.C.T.H. Compared with the Expected Results Assuming a Denervation Rate of $39 \%$

\begin{tabular}{ccccc|c|c|c}
\hline & & & & & Total & $\begin{array}{c}\text { Complete } \\
\text { Recovery }\end{array}$ & Denervation \\
\hline Actual. &.. &.. &.. &.. & 77 & 64 & 13 \\
\hline$\chi^{2}=14 \cdot 86, \mathrm{n}=1, \mathrm{P}<0.001$. & & & 47 & 30 \\
\hline
\end{tabular}

Delay in Starting Treatment.-It is believed that most of the damage in severe cases of Bell's palsy occurs in the first 48 hours (Langworth and Taverner, 1963). Early treatment is likely to be of prime importance. The results of the present series in relation to duration of the palsy are shown in Table IV. There is a smaller proportion of denervation in the patients treated less than 48 hours from the onset $(0.6>$ $\mathrm{P}>0.05)$.

Side-effects.-No side-effects from the A.C.T.H. were seen ; but one patient, previously depressed for some weeks, became elated during the period of treatment. Later he became more depressed than ever and had to receive psychiatric treatment, which was successful.

TABLE IV.-Relation Between Type of Response and Time of Starting Treatment with A.C.T.H.

\begin{tabular}{|c|c|c|c|c|c|c|}
\hline Days from Onset: & $0-1$ & 2 & 3 & 4 & 5 & Total \\
\hline $\begin{array}{ll}\text { omplete recovery } & \ldots \\
\text { enervation } & .\end{array}$ & $\begin{array}{r}14 \\
14\end{array}$ & $\begin{array}{r}16 \\
2\end{array}$ & $\begin{array}{r}15 \\
5\end{array}$ & $\begin{array}{r}12 \\
4\end{array}$ & 7 & $\begin{array}{l}64 \\
13\end{array}$ \\
\hline
\end{tabular}




\section{Discussion}

We believe that A.C.T.H. gel by intramuscular injection reduces the incidence of denervation in Bell's palsy to a substantial degree. All the treated patients were fully satisfied with their recovery except for one who developed complete denervation (Langworth and Taverner, 1963 ; Taverner and Fearnley, 1965). On clinical grounds we suspect that this patient was suffering from herpes zoster, which seems to be unresponsive to A.C.T.H.

The premature ending of the trial was unfortunate, but on ethical grounds we were not prepared to withhold treatment in order to strengthen our case at the cost of possible permanent damage to patients. Apart from the clinical results, we were aware on electrophysiological grounds that we were modifying the course of Bell's palsy in an unprecedented manner. In five patients conduction latencies of more than $4 \mathrm{msec}$. were obtained from the affected facial nerve on electrical stimulation, yet these patients recovered completely after A.C.T.H. therapy. Langworth and Taverner (1963) have shown that such values always presage denervation.

It is true that the patients treated later are a selected group, but the bias is against the treatment. The $30(41 \%)$ patients with only conduction block were excluded, but this ensures that the remainder contains a higher proportion than normal of patients likely to develop denervation if untreated. This claim is based upon the fact that at this stage the patients as a whole were unselected, successive patients attending with fresh Bell's palsy in whom about $40 \%$ are likely to develop denervation (see above). Twenty-seven of the treated patients (37\% of the total) had a raised threshold to anodal galvanic stimulation of the tongue when first seen. It has been shown by -Peiris and Miles (1965) that this always means that with standard treatment denervation is going to occur. Their work was completed before the present trial was started, and these patients treated with A.C.T.H. gel are the only exceptions to their findings we have ever seen.

The success of A.C.T.H. in preventing denervation contrasts with the failure of oral cortisone (Tavemer, 1954). This differential effect has been noted previously in neurological conditions (Jönsson et al., 1951 ; Alexander et al., 1958 ; Ross et al., 1958 ; Miller et al., 1961). Perhaps the pattern of hormones liberated by the patient's own suprarenal glands on stimulation lies behind this difference.

Our present policy is to treat all patients with Bell's palsy in whom there is any doubt about the likelihood of complete recovery, because of a raised threshold to anodal galvanic stimulation of the tongue. If the test is unsatisfactory, especially in older patients, then treatment is given anyway.
Patients with severe degrees of diabetes mellitus and congestive heart failure should probably be excluded.

We are satisfied that this form of treatment started on the first day of paralysis will virtually eliminate the often severe permanent disfigurement that has always been the grievous danger after Bell's palsy. This in turn removes the need to establish the value of surgical treatment (Langworth and Taverner, 1963).

\section{Summary}

The results of trials of the use of intramuscular A.C.T.H. gel in the treatment of idiopathic facial paralysis (Bell's palsy) are reported.

Preliminary results of a randomly selected controlled sequential trial with 34 treated and 36 control patients showed a benefit attributable to treatment significant at the $5 \%$ level, but in the final results the differences did not reach statistical significance.

The work was continued, a total of 77 patients being treated with A.C.T.H.-64 recovered completely and 13 developed denervation. From previous studies the expected results in 77 successive patients with Bell's palsy would be 47 complete recoveries and 30 with denervation. The difference is shown to be highly significant.

It is claimed that even better results would be obtained if all patients were treated within 24 hours of the onset of paralysis.

We thank Professor M. Hamilton for his invaluable help in the statistical aspect of this work. We are indebted to Mr. P. J. Burch for much theoretical discussion which led to the initiation of this trial to test a hypothesis. We are grateful to the many doctors who have referred patients so promptly. We are deeply grateful to the chairman and secretaries of the local health committees in Leeds, Bradford, Barnsley, Dewsbury, and the West Riding for their enthusiastic co-operation.

\section{REFERENCES}

Alexander, L., Berkeley, A. W., and Alexander, A. M. (1958). F. Amer. med. Ass., 166, 1943.

Armitage, P. (1960). Sequential Medical Trials. Blackwell, Oxford.

Fearnley, M. E., Rainer, E. H., Taverner, D., Boyle, T. McM., and Miles, D. W. (1964). Lancet, 2, 725.

Jönsson, B., Reis, G. von, and Sahlgren, E. (1951). Acta psychiat. (Kbh.), Suppl. No. 74, p. 60.

Krarup, B. (1958). Acta oto-laryng. (Stockh.), 49, 294.

Langworth, E. P., and Taverner, D. (1963). Brain, 86, 465.

Langworth, E. P., and Taverner, D. (1963). (1961). Lancet, $2,1120$.

Mosforth, J., and Taverner, D. (1958). Brit. med. F., 2, 675 .

Mosforth, J., and Taverner, D. (1958). Brit. med. J., 2, 675.
Peiris, O. A., and Miles, D. W. (1965). Ibid., 2, 11622.
Ross, It. Colmant, H. J., and Böhm, P. (1958). Dtsch. Z. Nervenheilk., Ross, J., Colman

Taverner, D. (1954). Lancet, 2, 1052.

(1955). Brain, 78, 209.

- (1959). Proc. roy. Soc. Med., 52, 1077.

- and Fearnley, M. E. (1965). Lancet, 1, 488.

Brit. med. F., 1966, 1, 393-396

The development and use of atomic energy have led to an increase in man's exposure to ionizing radiation, and there is general concern over the possible damage which might result from this increased exposure. Situations which give rise to large individual doses are extremely rare, and the major exposure is to low doses at very low dose rates. Large numbers of the general population are exposed to fallout at dose rates which average a few hundreths of a rad per year. A small

* Radiological Protection Service (Ministry of Health and Medical Research Council), Sutton, Surrey. section of the population are radiation workers and are exposed, occupationally, to higher doses; these amount, on average, to $1 \mathrm{rad}$ per year, or less. So far, harmful effects of low doses of radiation at low dose rates have not been detected, and the possible risks are estimated by extrapolating from the effects of high doses, delivered at high dose rates, and observed in studies of atomic-bomb survivors, and ankylosing-spondylitis patients who have been treated with ionizing radiation. This extrapolation introduces considerable uncertainty, which might be avoided by attempting to detect directly the effects of exposures 